\title{
Pictorial and Virtual simulation of Andrea Mantegna's fresco The Wedding Chamber through a mixed reality environment installation
}

\author{
Andres Montenegro \\ Department of Art and Design, Purdue University Fort \\ Wayne \\ montenea@pfw.edu
}

\author{
Audrey Ushenko \\ Department of Art and Design, Purdue University Fort \\ Wayne \\ ushenko@pfw.edu
}

\begin{abstract}
Andrea Mantegna's influence over the Renaissance's naturalistic rendition of the space is fundamental, and his works continued to inspire in the next centuries different schools of painting in Europe. His use of the concept of "Trompe L'oeil," [1] inaugurates a proto-technological system that expands the architectural space of the fresco's technique to illusionistic dimensions. However, recent studies have discovered that some of his frescos depict a more complex representation inspired by writers from the classical world, seeking to immerse the viewers in a more literary narrative and visual perceptions [2]. Those masterpieces followed an ambitious desire to play with illusion as a device to expand their pictorial narrative beyond their formal physical boundaries. That is the case expressed in the series of frescos located at The Palazzo Ducale di Mantova Italy.

These painted images are known as the "Camera Picta," "Wedding Chamber", or La Camera degli Sposi. A particular component of these frescos is the application of "di sotto in sù" (seen from below), which represents in a painted vaulted ceiling an opened sky seen through an oculus shape, depicting characters glancing down. Andrea Mantegna playfully organizes this effect and suggests a perception that goes beyond the mere effect of illusion articulating complex and opposed vantage points. The installation described in this paper commits a full and interactive approach to the topics described above.
\end{abstract}

\section{CCS CONCEPTS}

- Applied computing $\rightarrow$ Arts and humanities; Media arts.

\section{KEYWORDS}

Trompe L'oeil, Virtual Reality, Mixed Reality, Augmented Reality, Immersive Environment

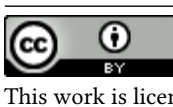

This work is licensed under a Creative Commons Attribution International 4.0 License.

ARTECH 2021, October 13-15, 2021, Aveiro, Portugal, Portugal

(C) 2021 Copyright held by the owner/author(s).

ACM ISBN 978-1-4503-8420-9/21/10.

https://doi.org/10.1145/3483529.3483771
ACM Reference Format:

Andres Montenegro and Audrey Ushenko. 2021. Pictorial and Virtual simulation of Andrea Mantegna's fresco The Wedding Chamber through a mixed reality environment installation. In 10th International Conference on Digital and Interactive Arts (ARTECH 2021), October 13-15, 2021, Aveiro, Portugal, Portugal. ACM, New York, NY, USA, 4 pages. https://doi.org/10. $1145 / 3483529.3483771$

\section{INTRODUCTION}

The fundamental goal of this installation is to create the reenactment of "La Camera Degli Sposi," "Camera Picta," or known as well as "Wedding Chamber" through a simulated rendition of Augmented Reality/ Virtual Reality (mixed reality), to study the illusionistic space used by Andrea Mantegna in the real fresco located in Mantua, Italy. This reenactment will be achieved by an install based on a collapsible and portable banners display, keeping the virtual space coordinates and measures, in terms of immersion, of the original room located at the Saint Giorgio Castle in Mantova, Italy. This immersive environment ${ }^{1}$ will render a conceptual development of the original fresco painted with mixed traditional media on its walls and ceiling. This interpretation of the real fresco will maintain its compositional structure through outlines and color deconstruction, just keeping the factual depiction of the oculus in the ceiling as a full reproduction of the original piece.

The painted elements will be associated or glued to a digital content of mixed reality [3] as image targets. Whenever a mobile device or wearable headset device (Microsoft HoloLens, Oculus Quest 2, HTC VIVE, iPad) points at the painted elements (targets) on the walls, it will display the holographic configuration of the fresco' scenes on the screen with fully animated details and enhancing the augmenting experience in HD cinematic realism.

\section{THE INSTALLATION VISUAL INTERFACE OUTCOMES}

This project can provide:

- 2.1 Seeing figures foreshortened from successive points of view.

- 2.2 Seeing the figures of the immersive fresco in motion.

- 2.3 Seeing figure inter-action within illusionistic space.

- 2.4 Seeing the illusionistic extension and enhancement of real architectural space.

\footnotetext{
${ }^{1}$ An artificial, interactive, computer-created scene or 'world' within which a user can immerse themselves. Examples Computer games (from simple arcade games to massively multiplayer online games), training (e.g., flight and driving simulators), entertainment environments, art installations, etc. http://medical-dictionary.thefreedictionary. com/Immersive+environment
} 
- 2.5 Experiencing interaction with the figures.

- 2.6 Increased understanding of visual communication.

- 2.7 Viewing stages of the fresco's construction in layers.

- 2.8 Viewing Figures from various viewpoints, interacting, and moving from one position to the next.

\section{THE ARTISTIC OUTCOMES OF THE INSTALLATION}

- 3.1 Experience the fresco's color deconstruction.

- 3.2 Seeing the figures of the fresco scene in 3D models.

- 3.3 Seeing the fresco's figures interacting within 3D space.

- 3.4 Architectural space and symbols transformed into 3D models.

- 3.5 Increased understanding of the original fresco's layout.

\section{THE TECHNOLOGICAL OUTCOMES OF} THE INSTALLATION

- 4.1 Translate the spatial coordinates of the fresco to three dimensional models.

- 4.2 Configure the animation of the elements present in the fresco.

- 4.3 Establish and determine targets (elements or object recognition) in the fresco for animated sequence for Augmented Reality/Virtual Reality (Mixed Reality)

- 4.4 Recreate a virtual model of the original dome containing its augmented elements for an illusionistic projection in a flat ceiling or an architectural flat surface.

- 4.5 Explore the whole story of the fresco by specific segments of augmentation.

- 4.6 The installation will be designed for a versatile, inexpensive, and expedite access to visualization.

- 4.7 Organize the layout of the oculus by layering animated components to experience from below the complex compositional vectors of the ceiling.

- 4.8 Achieve augmentations to obtain a cinematic rendition of the fresco lined up and linked with the graphic information spotted on the wall.

\section{IMPACT OF THIS INSTALLATION PROJECT}

The mixed reality environment constructed here, will offer the target audience an opportunity to engage with one of the most significant monuments from the Western artistic tradition. Users can easily hold and operate the installation devices. The audience will we able to consider the way Mantegna opened ways of communicating his style and the techniques of the fresco's construction. They will be able to consider the psychological power of Mantegna's images and the innovations of his fresco technique. Through this experience, users will be partaking in what is increasingly being referred to as "Digital Art History." The term describes a variety of innovative practices for incorporating interdisciplinary technologies into research and teaching; it is a core concern in the field at present. This construction will also be instructive in what is demonstrative methods in digital art and the interfacing of traditional representational skills with digital imaging. This understanding is crucial for today's audience to understand the scope and relevance of emerging technologies. This installation piece is not in itself a photogrammetry reconstruction of the original fresco located in Mantova; it is an engaging virtual work that study a great monument of art from the past.

\section{THE ANIMATION COMPONENT PROVIDED BY MIXED REALITY (AUGMENTED/VIRTUAL REALITY)}

After the visitor scan the banners' painted surfaces, the animation component will be activated according to the directions provided in using the devices. The figures on the walls will travel from group to group and into the center space of the install. From this view, the observer will come to understand the movement phase from one stable position to another (crucial in the realist portrayal of the figure,) and the way in which illusionistic decoration develops architectural space and orients the observer gaze into that space. The ceiling is depicted totally by animations explaining visually the illusionistic resource of the "Oculus," so prevalent in ceiling frescos of the Renaissance.

\section{SIGNIFICANCE AND CONTEXT OF THE INSTALLATION WITHIN RELEVANT DISCIPLINES}

The created project will provide to a wide range of artists, computer science, art historians, and other professionals interested in emerging technologies, an opportunity to collaborate but also serve to break down barriers by providing an instructive and entertaining example of such collaboration to a wide audience. Admittedly, it would be engineering and technology in the service of art but still should make the idea of such collaboration more tangible and give some notion of the opportunities it affords. More importantly, it will provide an idea of possible alternatives in teaching communication through visual imaging, and it will foster an understanding of the construction of realist illusionistic forms that is crucial to the use of art in science and technology.

\section{WHAT THE INSTALLATION HAVE DEVELOPED IN TERMS OF RESPONSIVENESS AND USER INTERFACE}

- 8.1 Advanced C\# programing development for interactive immersive experiences.

- 8.2 Complete implementation of a VR interface and usability.

- 8.3 The modeling of the 3D characters of the original fresco.

- 8.4 Advanced texturing and lighting of a Virtual Reality engine.

- 8.5 The creation of HUD (Head Up Display) for users' awareness inside the Virtual Reality world

- 8.6 Refinement of the concept of navigation inside the Virtual Reality world of the Wedding Chamber.

Another important component of engaging the audience is the familiarization with VR/AR interfaces following a compatible distribution required by the Oculus and Steam platform to display immersive environments.

The Wedding Chamber install has achieved the following components in terms of computing development: 


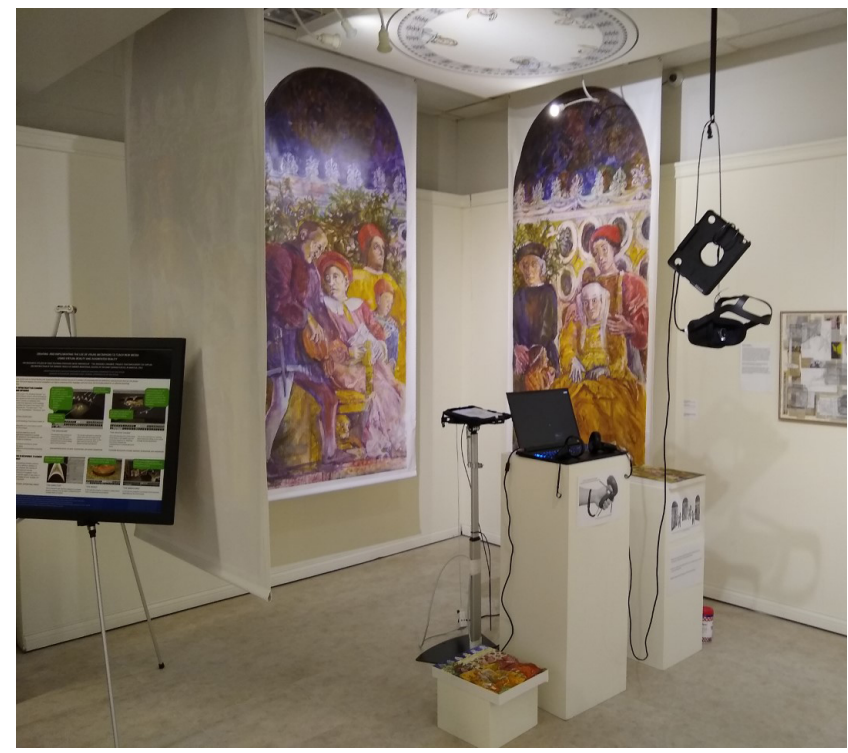

Figure 1: installation display presented at Purdue University Fort Wayne in February 2020.

- 8.7 Photorealistic 3D models of the fresco stage with animation.

- 8.8 Advanced texturing and normal mapping.

- 8.9 The design of a 3D theater to display animation concepts and renderings of the central oculus located in the ceiling of the Wedding Chamber.

- 8.10 Incorporation of Artificial Intelligences routines.

- 8.12 Incorporation of Responsiveness and Haptics [4] for users when they approach interactable objects.

- 8.13 Activation of pop-up cues and panels of information when users want to inquire more details of the object they are using.

- 8.14 Activation of physics when users collide with walls or unexpected objects.

\section{CONCLUSION}

The installation was presented at Purdue University Fort Wayne in Spring 2020. The installation integrates and provides for users' interaction the following systems:

Oculus Quest 2, HTC VIVE Pro, Microsoft HoloLens, Looking Glass 3D screen. Also includes iPad app for Augmented Reality target exploration. The enclosure space is $4 \mathrm{x} 4 \mathrm{mts}$, this represents the play area, where users can feel and experience the installation's boundaries. The install has been presented in several local venues and regionals as well. The effectiveness of interaction and responsiveness of the installation work depends heavily in users' feedback, for this reason, the associated study about user experience has become a critical component in terms of a seminal analysis of data. The collect of this information makes possible the improvement of future content development, and the strategies to implement an even more effective and expedite user's engagement with the installation.

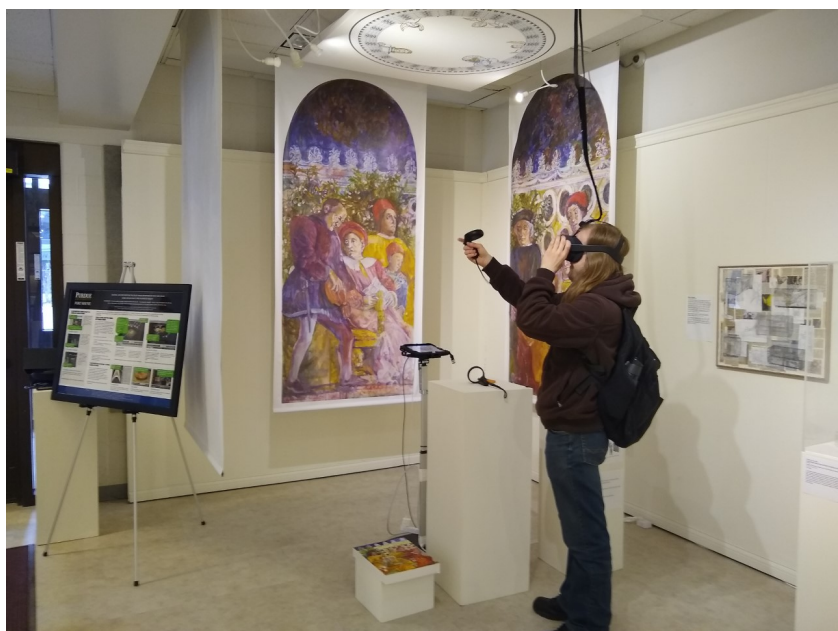

Figure 2: User interacting with VR/AR devices inside the installation

\section{ACKNOWLEDGMENTS}

City of Mantova. Sant Giorgio Castle. Italy.

Professor Rodolfo Signorini. Distinguished Italian scholar.

Department of Art and Design. Purdue University Fort Wayne.

Purdue University Fort Wayne Office of Sponsored Programs and University Research and Innovation

Indiana University Travel Research Grant

\section{REFERENCES}

[1] Oxford English Dictionary. Deception of the eye, an illusion, spec. in Art with regard to the material reality of the object(s) represented, a (usually still-life) painting, plaster ornament, etc., intended to give an illusion of reality. https://www-oed-com.ezproxy.library.pfw.edu/view/Entry/206648? redirectedFrom $=$ Trompe $+\mathrm{L} \% 27$ oeil $\#$ eid

[2] Lucian. 1972. Lucian of Samosata. The Works of Lucian. The Hall. A.M. Translation. Yale University. Harvard University Press. P176- 207

[3] Mixed reality (MR) (encompassing both augmented reality and augmented virtuality) refers to the merging of real and virtual to produce new environments and visualizations where physical and digital objects co-exist and interact in real- time. A mix of reality, augmented reality, augmented virtuality, and virtual reality. http://encyclopedia.thefreedictionary.com/Mixed+reality

[4] Oxford English Dictionary. Technology that provides a user interface based on the stimulation of the senses of touch and movement (kinaesthesia); the branch of science or engineering concerned with such technology. https://www-oedcom.ezproxy.library.pfw.edu/view/Entry/385304?redirectedFrom=haptics\#eid

[5] Rosella Vantaggi. 2015. Mantua and Her Art Treasures. Plurigraf Collection. Casa Editrice Perseus. World Publishing. Italy

[6] Stefano L'Ocaso. 2002. Il Palazzo Ducale Di Mantova. Editore Mondadori Elects. Italy

[7] Rodolfo Signorini. 2007. Opus Hoc Tenve. Publi Paolini. MP Marketing Publicita. Mantova, Italy

[8] Ugo Bazzotti. 2015. Palazzo Tew. Giulio Romano's Masterwork in Mantua. Thame Hudson. Italy

[9] Stephen Benton and Michael Bove. 2008. Holographic Imaging. A. John Wiley \& Sons, Inc., Publication. Wiley-Inter Science. Hoboken New Jersey

[10] Barry Blundell. 2007. Enhanced Visualization. Making Space for 3-D Images. Wiley-Inrterscience. A John Wiley \& Sons, Inc, Publication

[11] Jonathan Linowes. 2015. Unity Virtual Reality Projects. Community Experience Distilled. PACKT PUBLISHING. Open Source. Livery Place. Birmingham, UK

[12] Dominic Cushnan and Hassan El Habbak. 2013. Developing AR Games for iOS and Android. Develop and deploy augmented reality apps using Vuforia SDK and Unity 3D. PACKT Publishing. Open Source. Livery Place. Birmingham, UK 


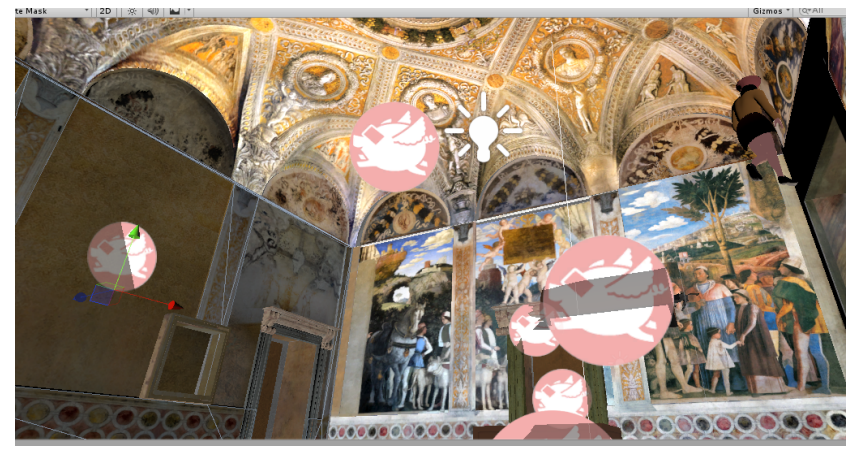

Figure 6: VR immersive snapshot of the Wedding Chamber interior.

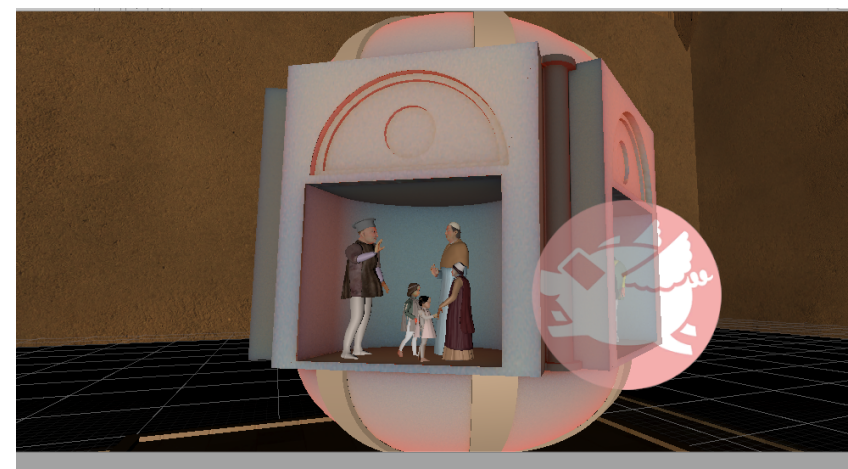

Figure 3: snapshot of VR environment with 3d animated scene.

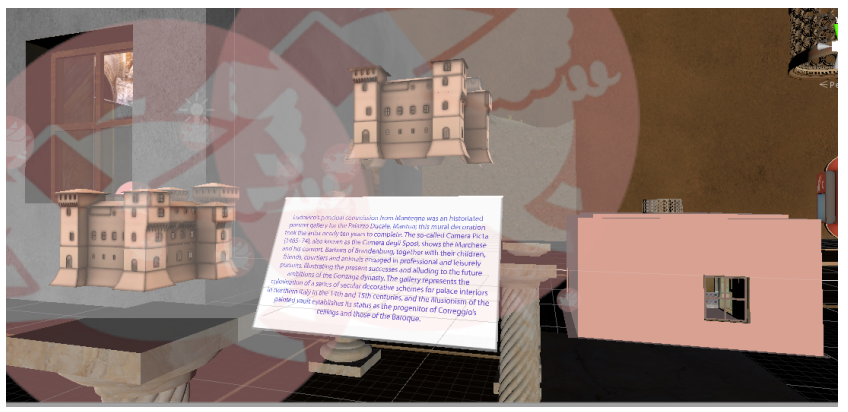

Figure 4: Snapshot of the VR immersion with study of architectural components.

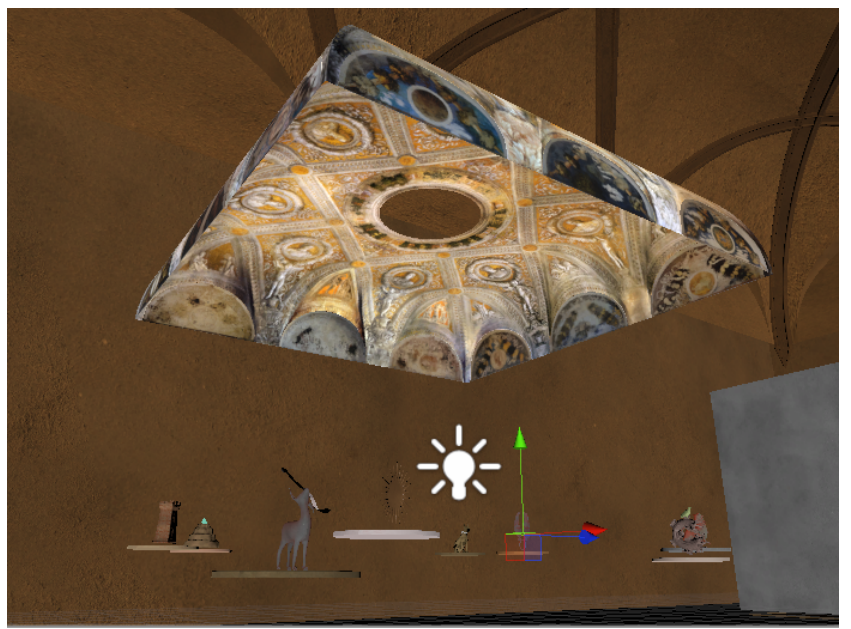

Figure 5: VR immersive detail of the fresco ceiling with oculus deconstruction.

\section{APPENDIX}

Snapshot of the VR experience using headset, controllers, and play area:

Systems included in the install: Three portable banners $3 \times 1.50$ mts. Oculus canvas 1.50 x $1.50 \mathrm{mts}$. Microsoft HoloLens. Alienware Laptop. Oculus Quest 2 plus controllers. iPad Pro. stand for iPad. 